\title{
Revisitando O LIVRO DA LILI: uma cartilha eficiente que combinava métodos de alfabetização
}

Stella Maris Bortoni-Ricardo*

Vera Aparecida de Lucas Freitas*

\section{Resumo}

As autoras refletem sobre suas experiências de alfabetizandas com o método "O Livro da Lili”, na década de 1950 em Minas Gerais. O trabalho combinava métodos sintéticos e analíticos de alfabetização.

Palavras-chave: Métodos de alfabetização; trabalho de Lúcia Casasanta; Minas Gerais; Reforma Francisco Campos.

Reviewing OLIVRO DALILI, an efficient primer which blended literacy teaching methods

\section{Abstract}

This article reviews a literacy primer, O livro da Lili, a pioneering method of the 1950's in Minas Gerais which combined both synthetic and analytical literacy teaching methods.

Keywords: Literacy teaching methods, Lúcia Casasanta, Minas Gerais, Francisco Campos reforms.

Neste artigo, as autoras refletem sobre suas experiências de alfabetizandas com o método O Livro da Lili, da década de 1950, em Minas Gerais. O Livro da Lili resultou de um trabalho de Anita Fonseca, aluna da professora Lúcia Casasanta, docente da Escola de Aperfeiçoamento, particularmente dedicada a formar professores alfabetizadores.

Os métodos de alfabetização geralmente se agrupam em duas categorias: os que trabalham com uma dinâmica conhecida como "de baixo para cima" (bottom-up) e os que desenvolvem uma dinâmica "de cima para baixo" (top-down). A primeira categoria também é identificada como a dos

* Professora da Faculdade de Educação da UnB. E-mail: stellamb@terra.com.br.

** Professora da Faculdade de Educação da UnB. E-mail: verafr@globo.com. 
métodos sintéticos, que se iniciam com o aprendizado das letras e dos sons correspondentes. A segunda, em oposição, é chamada de analítica e seu ponto de partida são textos completos, ainda que de curta extensão. Há bastante discussão disponível e controvérsia sobre a superioridade de uns ou outros, mas prevalece hoje em dia a concepção de que o método per se não é a variável mais importante no processo de alfabetizaçáo. Quando bem aplicados, métodos com diferentes pressupostos teóricos permitem obter igualmente bons resultados. Admite-se também, na atualidade, a conveniência de se combinarem métodos analíticos e sintéticos.

O Livro da Lili, discutido neste trabalho, foi pioneiro no Brasil nessa combinação das abordagens sintética e analítica. Como esperamos deixar claro, trata-se de metodologia muito bem-sucedida, que merece ser revisitada e analisada a forma como conciliou os dois modelos (FRADE; MACIEL, 2006).

Os métodos de alfabetização de orientação fonológica e estratégia sintética voltam-se para a decodificação da palavra, com base no desenvolvimento da consciência fonológica, isto é, trabalham a relação entre os sons distintivos da língua (fonemas) e a sua representação por meio de letras ou dígrafos. Em outras palavras, sua ênfase é a aprendizagem do princípio alfabético.

A esses métodos sintéticos opóe-se o paradigma analítico, conhecido nos países de língua inglesa como whole language (CLARK, 1999), e parte da premissa de que a leitura é um processo natural, como a fala. Todo o trabalho de alfabetização é feito com textos, especialmente textos espontâneos produzidos pelos alfabetizandos. Segundo esse paradigma, o contexto fornece pistas funcionais que permitem ao aprendiz "adivinhar" cada palavra. Esses métodos têm a grande vantagem de valorizar o papel do contexto, pois as palavras, vocalizadas ou escritas, ocorrem sempre inseridas em um contexto significativo. Seus defensores realçam o fato de que a comunicação humana não se dá por meio de palavras isoladas, salvo em situaçôes excepcionais.

Os métodos analíticos, que no Brasil são também identificados como construtivistas, trouxeram uma grande contribuição ao enfatizar as estratégias heurísticas que os aprendizes desenvolvem quando começam a escrever e a ler. No entanto, têm uma fragilidade: à medida que enfatizam a capacidade do leitor de "adivinhar" a palavra pelo apoio contextual, dão pouca ênfase ao ensino explícito da relação entre fonemas e grafemas, que facilita a decodificação (e posteriormente a codificação) de palavras. Para uma dis- 
cussão mais detalhada da polêmica entre os dois paradigmas de alfabetização, ver Chall (1967) e Magalhães (2005), discutidos em Brasil (2003) (Cf. BORTONI-RICARDO, 2006).

O início do processo de escolarização é um grande desafio para as crianças. É o momento em que elas passam pela experiência de conhecer um novo mundo, quando transitam da cultura de oralidade para o definitivo convívio com as letras. Aprender a ler e a escrever é um processo complexo. Exige a realização de multitarefas mentais, psicológicas, linguísticas e motoras, que envolvem memória, atenção, discriminação visual, coordenação, entre tantas outras.

Bem diferente dos depoimentos ouvidos frequentemente de amigos e até mesmo de alunos e colegas sobre experiências negativas no início de sua escolarização é este de Vera Freitas, uma das autoras deste artigo:

Lembro perfeitamente do periodo de minha alfabetização, que ocorreu na década de 1950. Eu tinha 7 anos completos e não havia frequentado a pré-escola. Matriculada em um colégio religioso em uma cidade do interior de Minas Gerais, fui diretamente para o $1^{\circ}$ ano primário, como era denominado naquela época. Tudo na escola era novo e surpreendente. Minha classe era muito grande, composta de 45 meninas e eu era a de número 43 na chamada.

Os primeiros dias de aula foram para a minha adaptação, e minha irmã mais velha assistia parte da aula comigo. Essa fase não durou muito, uns dois ou três dias, pois logo começaram as atividades escolares, e eu já estava mesmo ansiosa por elas. Recebi o material escolar. No meio dele havia um caderno de que eu gostava muito por ser quadriculado, era o de aritmética, que encapei em casa com a ajuda dos irmãos mais velhos. Da cartilha com a qual fui alfabetizada tenho as mais vivas e melhores lembranças que marcaram aquele momento mágico da minha vida: $O$ Livro de Lili.

No primeiro dia de aula em que tivemos atividade de leitura, a professora, que era uma religiosa, entrou na sala de aula com um enorme cartaz enrolado debaixo do braço. Desenrolou-o e ergueu-o bem alto, deixando-o pendurado na parede, sobre o quadro de giz, para que todas as alunas o enxergassem. Lá estava estampada a gravura de uma menina de trancinhas louras e amarradas com lacinhos, vestindo um vestido rodado, que achei muito bonito. Abaixo da gravura via-se um texto, que foi a minha primeira lição. A professora leu-o por inteiro para nós e depois leu-o novamente por partes, apontando as frases e pedindo que repetissemos, em voz bem alta, aquela primeira lição. Foi com muito entusiasmo que repetimos assim: 


\section{Lili}

Olhem para mim.

Eu me chamo Lili.

Eu comi muito doce

Vocês gostam de doce?

Eu gosto tanto de doce!

De pronto, aquela historieta me encantou, ou melhor, me seduziu porque a personagem dialogava diretamente comigo. Eu fiquei maravilhada de me engajar pela primeira vez em uma atividade de leitura na escola, de uma forma táo interativa. Seguindo a instruçáo da professora, relemos o texto por inteiro e depois parte por parte. Tinhamos a cartilha, que, na verdade, era um livro de pequenas historinhas. Recebiamos também uma folha igualzinha ao cartaz da parede para pintar a gravura e recortar o texto, sentença por sentença. Esta era a primeira etapa. Depois de reconhecidas no todo, recortávamos as sentenças em palavras, que posteriormente seriam fragmentadas em sílabas. Em seguida, tínhamos que remontá-lo tal qual o original, como se fosse um quebra-cabeça. Pintávamos a gravura e, ao final, tudo era guardado em um envelope. Essa era a dinâmica adotada em todas as liçóes. Náo me lembro de ter feito a mesma coisa para chegar às letras. Aprendi a distinguir as letras do alfabeto sem me dar conta de como isso aconteceu.

Esse trabalho pedagógico, vivenciado na alfabetização de ambas as autoras deste artigo, demonstra como o método analítico combinava naturalmente com atividades próprias dos métodos sintéticos, na medida em que os alfabetizandos identificavam e recortavam frases, palavras e sílabas e depois as juntavam recuperando o texto, que fazia sentido e constituía um gênero textual que os alunos começavam a conhecer.

As liçóes, na verdade, eram pequenos contos ilustrados, como se fossem um livro em capítulos. Muito agradáveis de serem lidas, muito interessantes para alunos de sete anos que estavam sendo iniciados na magia da leitura. Os contos continham tudo que poderia interessar às crianças da época. Reproduziam uma família com filhos, brinquedos, animais e uma cozinheira que fazia coisas gostosas. Lili tinha bonecas, uma cachorrinha, queria aprender a costurar, sabia fazer doce de abacaxi e tocar piano. $\mathrm{O}$ irmão, Joãozinho, tinha um automóvel e também um cachorro. O que mais poderia ser tâo interessante para uma criança? Não era difícil para os alfabetizandos da época se identificar com as personagens e com os temas daquelas histórias. 
A primeira lição da cartilha geralmente é reproduzida de memória por quem foi alfabetizado pelo livro de Anita Fonseca. Alguns se referem também à lição "O convescote", que transferia para o léxico mental dos alfabetizandos uma palavra rara em seu cotidiano. Eles relatam que, no período de dois a três meses, se surpreendiam lendo outros textos. O processo de aprender a ler era rápido, sem traumas e linguisticamente intuitivo.

As palavras que compunham os textos de $O$ Livro da Lili não eram difíceis. Em sua grande maioria formavam-se dentro do padrão silábico mais simples, ou seja, consoante e vogal (CV). Entretanto, havia também palavras formadas em padróes silábicos um pouco mais complexos, por exemplo, consoante, vogal, consoante (CVC); consoante, consoante e vogal (CCV) e outras constituídas de alguns dígrafos: lh, nh, ch, rr, ss. Isso, sem dúvida, não era o comum nas cartilhas tradicionais. Como os textos eram contos, já se introduziam sinais de pontuação (ponto final, vírgula, ponto de exclamação, ponto de interrogação e travessão, para marcar o discurso direto), que são usados para organizar o texto logicamente.

$\mathrm{Na}$ primeira lição, os alfabetizandos encontravam palavras com os padrôes silábicos CV; CVC em doce, gostam, tanto; e dígrafos em olhem e chamo, além de ditongo decrescente em muito.

Ressalte-se que O Livro da Lili foi sucesso editorial por três décadas, mas também recebeu críticas.

O método global foi implantado nas escolas públicas do estado de Minas Gerais a partir da Reforma Francisco Campos, implementada pelo governo mineiro em 1927-1928. Pretendia-se, com a reforma, melhorar a qualidade do ensino no estado e reverter a precária condição em que se encontrava a educação à época. Focalizar o ensino no desenvolvimento das habilidades de ler e escrever, mediadas por textos, em substituição à simples decodificação de palavras, e privilegiar o aluno nesse processo passaram a constituir o alvo e a essência da proposta do método em questáo.

A Reforma Francisco Campos tornou-se marco em Minas Gerais, pelas inovaçôes metodológicas para a alfabetização de crianças e pela polêmica e resistência que causou entre professores e pais de alunos. O novo método proposto era desconhecido dos alfabetizadores e eles náo contavam com formação atualizada e específica, apoio pedagógico e material adequado para sua aplicação, o que gerou uma forte insegurança nos professores (FRADE; MACIEL, 2006, p. 70-71). 
O rompimento com os métodos tradicionais fundamentava-se nos princípios pedagógicos do escolanovismo, que tinha por objetivo ter o estudante como centro de interesse da educação, levando-se em consideração o seu processo natural de desenvolvimento (FRADE; MACIEL, 2006, p. 96), contrariamente à escola tradicional, que se centrava no ensino e no professor. A Escola Nova foi um movimento com propostas de renovaçáo do ensino bastante forte na Europa e nas Américas, e no Brasil foi muito acolhido no estado de Minas Gerais. Educadores, estimulados por tais propostas pedagógicas, instituíram, no Rio de Janeiro, a Associação Brasileira de Educação - ABE, em 1924.

Em Minas Gerais, as reformas propostas pela $\mathrm{ABE}$, inspiradas no escolanovismo, foram conduzidas por Francisco Campos e Mário Casasanta. Em 1927, recursos do governo aplicados na educação concretizaram o movimento com a criação da Escola de Aperfeiçoamento em Belo Horizonte, que tinha por missão servir como multiplicadora da proposta e aprimorar a formação de professores alfabetizadores segundo a ideologia do novo método. Para atender à demanda de livros didáticos que contemplassem a novidade, a Escola de Aperfeiçoamento promoveu um concurso para a produção de uma cartilha segundo os princípios do método e que contivesse os requisitos ensinados pela professora Lúcia Casasanta no curso de formação de professores daquela escola. $\mathrm{O}$ vencedor do certame foi $\mathrm{O}$ Livro de Lili, testado nos anos de 1930 e posteriormente largamente adotado no estado de Minas Gerais.

O Livro de Lili, idealizado por Anita Fonseca e editado pela Editora e Livraria Francisco Alves - que à época da Reforma Francisco Campos atuava na produção de cartilhas nacionais no Rio de Janeiro, São Paulo e Belo Horizonte -, foi método hegemônico em Minas Gerais por cerca de aproximadamente três décadas (de 1940 a 1960). Essa cartilha insere-se na proposta do "método global de contos", que surge em substituição ao método silábico, o mais utilizado para a alfabetização no século IX e início do século XX no Brasil.

Enfim, pode-se avaliar o sucesso dessa obra pelo número de ediçóes que alcançou, pelo período em que foi adotado nas escolas públicas e particulares de Minas Gerais e pelas influências que exerceu na produção de outras cartilhas. Frade e Maciel (2006) fazem um levantamento minucioso dessas ocorrências. Entretanto, o método global recebeu críticas, sob o argumento de que a decifração não deve ser intuitiva e, em algum momento do processo de alfabetizaçáo, tem de ser racional. 
A metodologia para a alfabetização ainda é, no Brasil, um tema muito discutido e objeto de controvérsias. É, pois, interessante constatar que, há quase sessenta anos, pesquisadores de Minas Gerais já haviam chegado a uma proposta de método tão satisfatório e eficiente, como foi $O$ Livro da Lili

A alfabetização como objeto de estudo tem sido foco de inúmeras pesquisas, às quais remetemos a seguir os leitores interessados no tema: Castanheira; Maciel; Martins, 2008; Frade; Maciel, 2006; Soares, 2005; Carvalho, 2005; Bortoni-Ricardo, 2004; Cardoso-Martins, 1995; Abaurre-Gnerre 1984; Barbosa da Silva, 1981; Cagliari, 1996, 1998; Faraco, 1992; Kato, 1992; Lemle, 1987; Moraes, 2000; Scliar-Cabral, 2003; Tfouni, 1995; Kleiman, Signorini, 2000; Brasil, 2003.

\section{Referências}

ABAURRE-GNERRE, M. B. Regionalismo lingüístico e a contradição no intervalo. In: Seminário Multidisciplinar de Alfabetização. Anais... Brasília: MEC-Inep, 1984, p. 13-18.

BARBOSA DA SILVA, M. Leitura, ortografia e fonologia. São Paulo: Ática, 1981.

BORTONI-RICARDO, S. M. Educação em língua materna: a sociolingüística em sala de aula. São Paulo: Parábola, 2004.

. Métodos de alfabetização e consciência fonológica: o tratamento de regras de variação e mudança. Scripta, Revista do Programa de Pós-Graduação em Letras e do Centro de Estudos Luso-afro-brasileiros da PUC Minas, v. 9 n.18, p. 201-220, 2006.

BRASIL, Câmara dos Deputados. Grupo de trabalho alfabetização infantil: os novos caminhos - relatório final. Brasília, 2003.

CAGLIARI, Luiz Carlos. Alfabetização e lingüistica. São Paulo: Scipione, 1996.

- Alfabetizando sem o bá-bé-bi-bó-bu. São Paulo: Scipione, 1998.

CARDOSO-MARTINS, C. Consciência fonológica e alfabetização. Petrópolis, RJ: Vozes, 1995. 
CARVALHO, M. Alfabetizar e letrar: um diálogo entre a teoria e a prática. Petrópolis, RJ: Vozes, 2005.

CASTANHEIRA, M. L.; MACIEL, F. I. P.; MARTINS, R. M. F. Alfabetização e letramento em sala de aula. Belo Horizonte: Autêntica/Ceale, 2008.

CHALL, J. S. Learning to read: the great debate. New York: McGraw Hill, 1967.

CLARK, Lesley. Developing phonic skills in the early years. In: GOODWIN, P. (Org.) The literate classroom. Londres: David Fulton Publishers, p. 11-17, 1999.

FARACO, C. A. Escrita e alfabetizaçâo: características do sistema gráfico do português. São Paulo: Contexto, 1992.

FONSECA, A. Cartilha: O livro de Lili. Disponível em: <http://pt.scribd. com/doc/17623312/-A-Cartilha-de-Lili>. Acesso em: 10 fev. 2010.

FRADE, I. C. A. da S.; MACIEL, F. I. P. História da alfabetização: produção, difusão e circulação de livros (MG/RS/MT - Sec. XIX e XX). Belo Horizonte: UFMG/FaE, 2006.

KATO, M. A. (Org.) A concepção da escrita pela criança. Campinas, SP: Fontes, 1992.

KLEIMAN, A.; SIGNORINI, I. (Orgs.). O ensino e a formação do professor. Porto Alegre: Artmed, 2000.

LEMLE, M. Guia teórico do alfabetizador. São Paulo: Editora Ática, 1987.

MAGALHÃES, N. Conhecer a história dos métodos de ensino para alfabetizar no presente. Letra A - O jornal do alfabetizador. Belo Horizonte, 2005.

MORAES, A. G. de. O aprendizado da ortografia. Belo Horizonte: Autêntica, 2000.

SCLIAR-CABRAL, L. Princípios do sistema alfabético do português do Brasil. São Paulo: Contexto, 2003.

SOARES, M. Alfabetização e letramento. São Paulo: Contexto, 2005.

TFOUNI, L. V. Letramento e alfabetização. São Paulo: Cortez Editora, 1995. 


\section{ANEXO}

1. Lili

Olhem para mim.

Eu me chamo Lili.

Eu comi muito doce

Vocês gostam de doce?

Eu gosto tanto de doce!

2. Lili em seu piano

Lili toca piano.

Lili toca assim

Dó, ré, mi, fá...

Suzete é a cachorrinha.

Suzete ouve Lili tocar.

Toca Lili, toca dó, ré, mi, fá...

3. A cozinheira

Olhem esta cozinheira!

A cozinheira é a Lili.

Lili gosta de doce.

Ela faz doce de abacaxi.

Joãozinho, você quer doce?

Você gosta de doce de abacaxi?

4. As meias de Lili

Eu vou calçar as minhas meias

As minhas meias são azuis.

Que pena! A minha meia tão

bonita está furada!

Eu não sei coser!

Como há de ser? 
392 Polyphonía, v. 21/2, jul./dez. 2010

5. As bonecas de Lili

Lalá, Bebê, Clarinha.

Lili dizia dorme assim nã, nã, nã.

Eu também vou dormir.

6. (Sem título)

Lili está brincando com a boneca.

A boneca fica de pé.

Lili fala para a boneca:

Anda, anda, Lalá!

Lalá anda, anda.

Lili pega Lalá.

7. (Sem título)

Eu me chamo Joãozinho.

Este automóvel é meu.

Meu automóvel faz assim: fon-fon.

Totó passeia comigo.

Totó é o meu cachorrinho.

Você quer passear no meu automóvel, Lili?

Recebido em: 20 abr. 2011

Aceito em: 30 maio 2011 